\title{
Representaciones de cuatro carreras de la Universidad de Buenos Aires y su vínculo con el abandono de estudios
}

Andrés Santos-Sharpe

RESUMEN

El artículo analiza la relación entre el abandono universitario y las representaciones sociales en torno a cuatro carreras de la Universidad de Buenos Aires (UBA): Ciencias de la Comunicación, Ciencias Químicas, Antropología e Ingeniería en Informática. Entendemos que las representaciones sociales construyen un sentido en el que se condensan y articulan múltiples enunciaciones e interpretaciones en relación con las carreras analizadas y que intervienen en modos específicos de discontinuar los estudios superiores. Como conclusiones no sólo distinguimos las distintas representaciones en cada carrera, sino que vimos los modos diferenciados en que operan con relación a la experiencia estudiantil.

Palabras clave: representaciones sociales, expectativas del estudiante, experiencia educativa, cultura profesional, deserción, Argentina.

\section{Andrés Santos-Sharpe}

andres_iss@yahoo.com.ar

Argentino, Doctor en Ciencias Sociales, Licenciado y Profesor en Ciencias de la Comunicación por la Universidad de Buenos Aires (UBA), Argentina. Docente, Ciencias de la Comunicación, UBA, y becario posdoctoral del Consejo Nacional de Investigaciones Científicas y Técnicas (CONICET), con sede en el Instituto de Investigaciones Gino Germani (IIGG), Argentina. Temas de investigación: análisis de las culturas disciplinares y de las experiencias de los sujetos que participan en la institución universitaria. ORCID: 00000003-4747-3692. 


\section{Representações de quatro carreiras da Universidad de Buenos Aires e seu vínculo com o abandono de estudos}

\section{RESUMO}

O artigo analisa a relação entre o abandono universitário e as representações sociais em torno de quatro carreiras da Universidad de Buenos Aires (UBA): Ciências da comunicação, Ciências Químicas, Antropologia e Engenharia em Informática. Entendemos que as representações sociais constroem um sentido no qual se condensam e articulam múltiplas enunciações e interpretações em relação às carreiras analisadas e que intervêm em modos específicos de descontinuar os estudos superiores. Como conclusões não só distinguimos as diferentes representações em cada carreira, mas também vimos os modos diferenciados em que operam com relação à experiência estudantil.

Palavras chave: representações sociais, expectativas do estudante, experiência educativa, cultura profissional, abandono, Argentina.

\section{Representations of four degrees at the University of Buenos Aires and their link to dropout rates}

\section{ABSTRACT}

This article analyzes the relationship between university dropout and social representations about four careers at the University of Buenos Aires (UBA): Communication Sciences, Chemical Sciences, Anthropology and Computer Engineering. We understand that social representations construct a meaning in which multiple enunciations and interpretations are condensed and articulated in relation to the careers analyzed and that they intervene in specific ways in the discontinuity of the students' higher education studies. As conclusions, we not only distinguished the different representations in each career, but also saw the differentiated ways in which they operate in relation to the student experience.

Keywords: social representations, student expectations, educational experience, professional culture, dropout, Argentina. 


\section{Introducción}

Este artículo presenta los resultados de una investigación realizada en el marco de la tesis de doctorado "Discontinuar los estudios en la universidad. Un estudio comparativo sobre la experiencia del abandono en cuatro carreras de la Universidad de Buenos Aires (UBA)". Particularmente, interesa recuperar de dicho trabajo la relación entre representaciones sociales previas sobre determinadas carreras y facultades y el abandono universitario.

En dicha investigación, partimos de la idea de que las representaciones sociales construyen un sentido en el que se condensan y articulan múltiples enunciaciones e interpretaciones en relación con las carreras analizadas. En muchos casos exceden a la presentación institucional que hace la facultad y la universidad sobre sí mismas; remite a un campo semántico más amplio que nos habla sobre la historia de la disciplina, los mitos asociados a ella, su prestigio acumulado, su relación con el mercado laboral en función del contexto más amplio vinculado con la situación del país, la economía y los debates societales y, por supuesto, en relación con la posición de quien experimentar dicha representación. Esos aspectos, más de tipo subjetivo, nos dieron indicios de cómo y por qué los sujetos analizados discontinuaban sus estudios universitarios.

En relación con lo anterior, presentamos aspectos de la investigación que involucran la dimensión representacional en cuatro carreras de la UBA: Ciencias de la Comunicación, Ciencias Químicas, Antropología e Ingeniería en Informática. Para ello, organizamos el artículo de la siguiente manera: luego del apartado teórico metodológico, en un segundo apartado definiremos los principales elementos de análisis. Por un lado, describiremos tipos de representaciones identificados y el proceso de su construcción. En el siguiente apartado se realizará el análisis de cada carrera identificando las representaciones que más intervienen en la discontinuidad de los estudios, cuál es el tipo representacional que prevalece en cada carrera y a qué se debe en cada caso; después analizamos si la transformación de dicha representación, las nuevas relaciones que establece o sus nuevas significaciones se relacionan con momentos de los tiempos institucionales o con turning points en el tiempo experiencial. Finalmente, un apartado final dará las conclusiones principales del estudio.

\section{Aspectos teóricos-metodológicos}

En este apartado, daremos cuenta en primer lugar de los conceptos principales utilizados en el análisis (abandono universitario y representaciones) para después referirnos a la estrategia metodológica.

\section{Conceptualización del abandono}

Según autores como Panaia (2013: 21) la literatura sobre el abandono universitario construyó un sujeto empírico de "abandonador" que se "desvincula" de la universidad y "fracasa" en cumplir el objetivo de la "conclusión" de la carrera. En ese sentido, el uso del concepto de discontinuidad en nuestra investigación se enmarca en una discusión más amplia, más que otros como abandono o deserción. Foucault utilizó el concepto de discontinuidad en La arqueología del saber (2002) a modo de crítica a los análisis históricos clásicos que se centraban en estudiar la continuidad en los hechos históricos (2002: 5) y cuando encontraban una ruptura la calificaban como una "dispersión que ningún horizonte previo podría encerrar" (2002: 340), como si las continuidades fuesen lo recurrente y las rupturas la excepción. Foucault se esforzaba por demostrar que la discontinuidad no era una anomalía en la historia, sino que "es un juego de transformaciones específicas [...] ligadas entre ellas según esquemas de dependencia" (Foucault, 1994: 680).

Recuperando esa expresión, interesa enunciar que la discontinuidad de los estudios universitarios no es una anomalía, sino que es un fenómeno que permite explicar un cúmulo de relaciones sociales que van más allá de la decisión (tradicionalmente considerada como individual) de dejar los estudios universitarios. 
Esto incluye los sentidos sociales y particulares otorgados a esa decisión y cómo la consecución de un proyecto de vida ligado a un ejercicio profesional o académico no necesariamente está indisolublemente ligado a la continuidad de los estudios.

Denominar al fenómeno analizado como "discontinuidad" implica, por lo menos, dos cuestiones importantes a destacar: primero, un modo de pensar a los sujetos no como individuos que toman decisiones autónomas más allá del contexto, sino como actores que participan en un escenario social pero que no necesariamente se guían por lo esperado socialmente sobre ellos.

Segundo, pensar el fenómeno como "discontinuidad de los estudios" nos permitía observar cuáles eran los modos en que los sujetos construían otras formas de "continuidad" sin que la persona que lleva adelante la investigación las defina, a priori, en términos de éxito o fracaso. Estos significados atribuidos al paso por la universidad sólo podíamos observarlos a partir de los relatos de vida, estrategia metodológica (Bertaux, 1999) elegida para el análisis. En síntesis, nos interesaba dar cuenta de la discontinuidad de los estudios universitarios recuperando relatos retrospectivos sobre la propia experiencia. Hemos detallado el debate sobre las diferentes maneras de analizar la discontinuidad de los estudios universitarios más in extenso en Santos Sharpe (2019).

\section{Representaciones sociales y tipos de representaciones en la discontinuidad}

En la elección teórica del concepto de representaciones en lugar de otros igualmente extendidos descartamos otras tradiciones en el análisis de la dimensión simbólica de la construcción del sentido social como las nociones de "representaciones colectivas" en la tradición durkheimiana, o la de "imaginarios sociales" con base en la distinción que plantean Sautu, Boniolo y Perugorría (2007).

En el caso de los imaginarios sociales, las autoras explican que designan el conjunto de representaciones globales y totalizadoras de una sociedad, como conjunto de valores, creencias, ideas y símbolos, que conforman lo cultural y lo simbólico. Las autoras distinguen el concepto de imaginarios sociales del de representaciones en tanto que este último supone una forma de pensamiento que surge del consenso social como resultado de interacciones y comunicación entre individuos, compartido socialmente por un grupo o comunidad. En otras palabras, son esquemas de pensamiento que permiten interpretar, organizar y entender la realidad que los rodea.

Dentro del concepto de representación social, y según el estudio de Maricela Perera Pérez (2003), se pueden identificar tres corrientes: la escuela de Ginebra con referentes como Willem Doise; el abordaje estructural liderado por Jean-Claude Abric; y la teoría de las representaciones sociales de Denise Jodelet y Sergei Moscovici. Para el presente trabajo recuperamos la perspectiva de Moscovici y Farr (1984), quien explica las representaciones sociales de la siguiente manera: "en el sentido clásico, las representaciones colectivas son un mecanismo explicativo, y se refieren a una clase general de ideas o creencias [...] Fenómenos específicos que se relacionan con una manera particular de entender y comunicar - manera que crea la realidad y el sentido común" (Moscovici y Farr, 1984: 3-63).

Abordajes más recientes, como el caso de Ivana Marková (1996), ponderan en el análisis la idea de que las representaciones sociales permiten simbolizar un "mundo estable" para los sujetos que los transforma, pero que al mismo tiempo esa representación sobre el propio entorno se reconfigura permanentemente "a través de las actividades de los individuos". De ahí que la experiencia de los sujetos es central a la hora de analizar cómo representan el mundo.

Así, encontramos en el concepto de representación social una noción que nos permite pensar un emergente central de las entrevistas realizadas: como las ideas previas respecto de la institución (universidad y facultad), pero principalmente respecto de la 
carrera y la disciplina, organizaban un conjunto de expectativas respecto de la futura experiencia universitaria. Asociado a ello, se articulan también las representaciones respecto de cómo serán proyectos de vida una vez finalizada la carrera; y las valoraciones sobre el modo en que se organiza y se enseña la disciplina en su forma institucionalizada (la carrera), que dan cuenta de construcciones simbólicas que las personas entrevistadas asociaron a la disciplina.

\section{Una tipología sobre las representaciones de las carreras analizadas}

En todos los casos, las personas entrevistadas narraron sus ideas previas al ingreso a la universidad, en general refiriéndose a la carrera elegida y luego ello aparecía en los relatos en contraste con la experiencia estudiantil en dicha carrera. Sin embargo, vale aclarar que la comparación de las representaciones previas sobre la carrera con la experiencia estudiantil no siempre supone una diferencia. En el análisis encontramos tres maneras en las que se expresan las representaciones: primero, aquellas que sí se manifiestan en términos de una oposición. Esto sucede cuando el sujeto tiene una representación previa sobre la carrera elegida y su experiencia estudiantil fue diferente a aquello que esperaba. Un ejemplo que desarrollaremos en el análisis aparece en quienes pensaban que la carrera de Ciencias de la Comunicación era igual a periodismo, y luego manifestaron que en su experiencia universitaria encontraron algo distinto.

En segundo lugar, encontramos aquellos relatos que manifiestan una disociación entre algún aspecto de la carrera y la experiencia estudiantil, pero no supone una diferenciación total, sino modifica el significado otorgado a algún aspecto en particular. Por ejemplo, quienes se representaban que la carrera de Química estaba orientada a la investigación en general lo confirmaron, pero manifestaron que esperaban algo distinto respecto de lo que implicaba "ser investigador".

En tercer lugar, encontramos representaciones previas que no sufren modificaciones significativas comparadas con la experiencia estudiantil, pero cobran otro significado. Por ejemplo, la representación de que las Ingenierías son difíciles es algo compartido. Sin embargo, lo que para algunos en el momento de la elección de la carrera era enunciado como una marca de orgullo, más adelante en sus trayectorias perciben cierta imposibilidad de finalizarla. Éstos son los tipos de representaciones que identificamos en los relatos (es decir, fueron categorías diferidas construidas a partir del análisis), y se manifiestan de distintas maneras en cada una de las carreras (tabla 1).

Los tipos de representaciones identificadas en los relatos manifiestan alguna clase de transformación a lo largo del tiempo y difiere según carrera y facultad en su relación con la discontinuidad y en el tipo representacional al que se inscribe. Esto motivó a indagar sobre qué procesos involucraban dichas transformaciones. ¿Cómo, cuándo y por qué enunciaron que lo que pensaban de la carrera era, desde su punto de vista, equivocado? ¿Por qué el sentido asociado a la disciplina tuvo en el momento de la entrevista otro significado?

\section{Tabla 1. Tipos de representaciones identificadas en los relatos}

\begin{tabular}{|l|l|l|}
\hline \multicolumn{1}{|c|}{ Representaciones en colisión } & Representaciones con nuevo sentido otorgado & Representaciones mantenidas \\
\hline $\begin{array}{l}\text { Se refiere a las representaciones previas sobre la } \\
\text { carrera, su campo de conocimiento, la cultura dis- } \\
\text { ciplinar, la universidad, la facultad, la posible salida } \\
\text { laboral y la vida estudiantil en general que luego } \\
\text { los entrevistados mencionaron que eran erradas } \\
\text { o que no se condecían con su experiencia estu- } \\
\text { diantil. }\end{array}$ & $\begin{array}{l}\text { Son aquellas representaciones que se mantienen } \\
\text { formaciones en su significado. }\end{array}$ & $\begin{array}{l}\text { Involucra a las representaciones que son confir- } \\
\text { madas por la experiencia estudiantil, pero que } \\
\text { aun así tienen impacto en la discontinuidad de } \\
\text { los estudios porque tuvieron un alcance distinto } \\
\text { al esperado en la experiencia estudiantil. }\end{array}$ \\
\hline
\end{tabular}

Fuente: elaboración propia. 
Estas transformaciones de las representaciones a menudo estaban vinculadas con un "momento institucional" (por ejemplo, la cursada de una materia en particular), pero también con distintas experiencias estudiantiles: algunas que transitan más el espacio universitario (como la sociabilidad estudiantil en el comedor de la facultad o en las agrupaciones políticas) y otras en su relación con prácticas sedimentadas (como un paro docente o una toma de facultad). El cruce entre la experiencia estudiantil y las representaciones, permitían suponer a modo de hipótesis que el peso de cada tipo de representación varía en cada carrera.

De cada uno de estos tres tipos de representaciones hay distintos casos en cada carrera analizada, y tienen implicancias en la discontinuidad o en la permanencia en su relación con otras representaciones y con la experiencia estudiantil, la cual difiere en función del sujeto en particular, de la institución y de la etapa de la carrera.

\section{Carreras seleccionadas y construcción de la muestra}

La elección de estas carreras por sobre otras estuvo motivada por distintas razones. Uno de los presupuestos teóricos de la tesis es la idea de que la experiencia estudiantil (Carli, 2012) de quien cursa una carrera, digamos por caso una de "exactas", es distinta a la de alguien que cursa una de "humanidades". Otra categoría sobre la cual organizamos la elección de las carreras fue la distinción entre las disciplinas de perfil más "profesional" y las de perfil "académico" o "científico".

Estas diferencias entre los tipos de disciplinas universitarias tienen relativo consenso entre los estudios sobre universidad a partir de la obra de Tony Becher, Tribus y territorios académicos (2001). En su libro, Becher propone una categorización de las disciplinas que le permite articular las características del tipo de conocimiento producido en ellas y las prácticas académicas de sus miembros. La dinámica producida en esa articulación la denomina "cultura disciplinar". Sin ahondar demasiado en las características epistémicas de Becher, las carreras elegidas nos permitían analizar experiencias y representaciones estudiantiles a partir de la diferenciación que aparece en la tabla 2.

El objetivo de seleccionar diversas carreras de acuerdo con la tipología de Becher se basa en el supuesto de que las distintas culturas disciplinares dan lugar a diferentes experiencias estudiantiles y eso interviene en una serie de dimensiones como las formas de sociabilidad o en las proyecciones a futuro que sus estudiantes construyen en relación con la carrera.

Considerando ello, la investigación se elaboró como un tipo de estudio cualitativo, exploratorio y sincrónico, con un método de abordaje biográfico en su modalidad del análisis temático de relatos de vida (life stories). La técnica desarrollada para el acceso a dichos relatos fueron entrevistas en profundidad abiertas o no directivas. La unidad de análisis se delimitó en relatos de jóvenes que hayan discontinuado sus estudios superiores en la UBA en cuatro carreras de distintas facultades con índices de abandono elevados entre los años 2005 y 2015: Ciencias Antropológicas, Ingeniería en Informática, Ciencias Químicas y Ciencias de la Comunicación. La unidad de observación para el análisis fueron los textos de entrevistas realizadas por el autor de la investigación.

Tabla 2. Dimensión cognitiva en la cultura disciplinar según Becher (2001)

\begin{tabular}{|c|c|c|}
\hline Dimensión Cognitiva & Pura (o académica) & Aplicada (o profesional) \\
\hline Blanda (o humanística) & Antropología & Comunicación \\
\hline Dura (o de exactas) & Química & Informática \\
\hline
\end{tabular}

Fuente: elaboración propia. 
En este sentido, la construcción de la muestra fue intencional por criterios teóricos bajo los siguientes atributos controlados: 1) año en que manifestaron discontinuar los estudios, 2) universidad, y 3) carrera discontinuada. Con esos criterios definidos, se seleccionaron sujetos para la muestra de manera tal que hubiese cuotas de personas entrevistadas por carrera, género y momento de la carrera en que discontinuaron (al principio de la carrera, a mitad o al final). Con esas consideraciones, los criterios que se tomaron para definir la muestra para hacer las entrevistas fueron:

- Que hayan discontinuado los estudios entre los años 2005 y 2015

- Que sean jóvenes universitarios

- Que esté equilibrada numéricamente en función del género

- Que considere los distintos momentos de la carrera (es decir, personas que hayan dejado al principio, a la mitad y al final de la carrera).

En primer lugar, el decenio elegido responde a un periodo relativamente estable en la UBA con relación a los niveles de inscripción, abandono e inversión según información provista por la Secretaría de Políticas Universitarias. Si hubiésemos tomado, por ejemplo, casos entre los años 2000 y 2010, tendríamos que haber considerado la variable de la crisis económica argentina de 2001/2002 en el análisis. Como no era interés de los objetivos de esta investigación explicar la discontinuidad de los estudios en tiempos de crisis, elegimos tomar un periodo de tiempo que no estuviese atravesado por cambios abruptos en materia económica.

En segundo lugar, nos interesaba entrevistar a jóvenes - y por tanto, no considerar en el estudio a los adultos mayores - , primero porque se trata del grueso del cuerpo estudiantil universitario en la UBA; segundo, porque este actor social construye otro tipo de vínculo con la universidad y de expectativas profesionales vinculadas a determinados proyectos de vida.

Finalmente, nos interesaba que las personas entrevistadas dieran cuenta de la diversidad de experiencias vinculadas con las distintas etapas de la carrera en las que se define la discontinuidad de los estudios, e interesaba considerar la dimensión de género con el fin de incursionar en los modos de construcción identitaria y sus efectos performativos en las experiencias de los sujetos.

El acceso a la trama de los relatos de jóvenes que discontinuaron sus estudios en las cuatro carreras seleccionadas se realizó por vía de entrevistas abiertas en profundidad a través de las cuales "el investigador extrae una información de una persona. Pero no cualquier información, sino aquella que se halla contenida en la biografía del entrevistado, es decir, aquella que se refiere al conjunto de representaciones asociadas a acontecimientos vividos por él" (Marradi et al., 2007: 218) con el objetivo principal de que las categorías sean aportadas por los mismos relatos y no definidas a priori por quien realiza la investigación (ver tabla 3). 
Tabla 3. Número de entrevistados/as según carrera en función de los criterios de conformación de la muestra

\begin{tabular}{|c|c|c|c|c|c|}
\hline & & $\begin{array}{l}\text { Ciencias de la } \\
\text { Comunicación }\end{array}$ & $\begin{array}{l}\text { Ingeniería en } \\
\text { Sistemas }\end{array}$ & Ciencias Químicas & $\begin{array}{c}\text { Ciencias } \\
\text { Antropológicas }\end{array}$ \\
\hline Total de entrevistados & & 16 & 8 & 11 & 8 \\
\hline \multirow{2}{*}{ Género } & Varón & 6 & 6 & 3 & 4 \\
\hline & Mujer & 10 & 2 & 8 & 4 \\
\hline \multirow{3}{*}{ Región de origen } & CABA & 6 & 3 & 6 & 3 \\
\hline & GBA & 8 & 3 & 5 & 2 \\
\hline & Otras & 2 & 2 & 0 & 3 \\
\hline \multirow{5}{*}{ NSE } & Bajo & 1 & 0 & 1 & 0 \\
\hline & M-вајо & 3 & 3 & 5 & 3 \\
\hline & Medio & 5 & 1 & 2 & 4 \\
\hline & M-Alto & 5 & 2 & 2 & 0 \\
\hline & Alto & 2 & 1 & 0 & 1 \\
\hline \multirow{4}{*}{ Colegio de procedencia } & Privado católico & 4 & 1 & 2 & 1 \\
\hline & Privado laico & 4 & 2 & 2 & 2 \\
\hline & Público & 6 & 3 & 7 & 4 \\
\hline & Universitario o nacional & 2 & 2 & 0 & 1 \\
\hline \multirow{4}{*}{$\begin{array}{c}\text { Instancia en que dejaron } \\
\text { los estudios }\end{array}$} & $\mathrm{CBC}$ & 1 & 0 & 2 & 0 \\
\hline & Inicio & 6 & 2 & 5 & 2 \\
\hline & Mitad & 6 & 2 & 3 & 3 \\
\hline & Final & 3 & 4 & 1 & 3 \\
\hline
\end{tabular}

Fuente: elaboración propia. 
Para el análisis se realizaron entrevistas en profundidad a 43 jóvenes que discontinuaron sus estudios universitarios en las carreras de Ciencias de la Comunicación, Ciencias Antropológicas, Ciencias Químicas e Ingeniería en Informática entre los años 2005 y 2015, además de análisis de documentos, fuentes oficiales, planes de estudio y entrevistas a informantes clave.

El acceso a la experiencia de los sujetos entrevistados se realizó por la vía de los relatos de vida (Bertaux, 1999) de jóvenes que discontinuaron sus estudios universitarios utilizando como técnica entrevistas en profundidad. A partir de ahí, se realizó un análisis temático de los relatos (Boyatzis, 1998) en la medida en que nos permitía comprender cómo los sujetos hacen inteligible la decisión de discontinuar los estudios, recuperando los diferentes momentos y acontecimientos biográficos que de esa manera alivianan, endurecen o directamente quitan la carga de responsabilidad al individuo.

Considerados los principales elementos metodológicos, en el siguiente apartado se analizarán las cuatro carreras por separado con énfasis en qué representaciones y proyecciones pesaron más en los distintos procesos de discontinuidad. Esto implica conocer también los sistemas de relaciones en los que esas representaciones se inscriben para dar cuenta de su vínculo con los procesos de discontinuidad y analizar las transformaciones que sufrieron en los tiempos de la experiencia universitaria, lo cual implica entender las construcciones simbólico-representacionales en la sociabilidad estudiantil. Hacia el final del artículo, pondremos en común las diferencias y semejanzas entre las cuatro carreras.

\section{Análisis de las representaciones de las carreras \\ Ciencias de la Comunicación}

La reconstrucción de las representaciones previas al ingreso a las carreras por parte de los estudiantes es un tema poco trabajado en la investigación social en educación. Si bien hay antecedentes en otros países, como el estudio "Imaginarios sobre comunicación" de Rizo García (2012) en México, específicamente en relación con Ciencias de la Comunicación de la UBA el único antecedente se encuentra en el libro Práctica profesional: satisfacción y malestar en el trabajo. Práctica docente en Ciencias de la Comunicación (Ferrarós di Stéfano, 2010), donde se trabajan las imágenes previas sobre dicha carrera aunque no en relación con la discontinuidad de los estudios, sino sobre el ejercicio profesional. Algunas de las conclusiones de dicho trabajo indican que:

una de las causas de sufrimiento más recurrente es la falta de reconocimiento por parte de la sociedad y, por lo tanto, de las organizaciones que podrían requerir de sus servicios, de las competencias propias de esta profesión. Las representaciones que "los demás", "los otros" (profesionales, instituciones, usuarios, etc.) tienen acerca de la práctica y funciones que podría desempeñar el comunicador están asociadas a los medios masivos, a la figura del "comunicador social", "periodista" o "publicista" (Ferrarós di Stéfano et al., 2010: 101).

Estas conclusiones se asemejan a nuestras primeras indagaciones en el campo: la representación social respecto del estudiante de Ciencias de la Comunicación es el de alguien que estudia periodismo o publicidad. De la misma manera se expresan Canessa et al. en Las representaciones sociales de los aspirantes a ingresar a la UBA. La universidad, el CBC y las carreras (2002), quienes en dicho informe del Departamento de Orientación Vocacional del (UBA) mencionan, respecto de la carrera de Ciencias de la Comunicación, que "los estudiantes la identifican [a Comunicación] como la carrera de 'periodismo o publicidad' (Canessa et al., 2002).

En el caso de las 16 personas entrevistadas de la carrera de Comunicación, encontramos bastante heterogeneidad en los siguientes criterios: ocho eran de 
distintas localidades del Conurbano, seis de Capital, uno de La Pampa y una de Mar del Plata, pero pasado un año o menos, diez se habían mudado a Capital solos o con amigos o amigas. La auto-afiliación de clase fue de dos de clase alta, cinco de clase mediaalta, cinco de clase media, tres de clase media-baja y uno de clase baja. Diez de las personas entrevistadas tenían al menos uno de sus padres con título universitario, cinco con terciario o universitario incompleto y sólo uno con padres con secundario.

En cuanto a su formación previa, cuatro egresaron de un colegio católico privado, cuatro de uno privado laico, ocho de un colegio público (uno especificó que fue a un técnico y otra a un ex nacional). Nueve de las personas entrevistadas trabajaron en relación de dependencia gran parte de la carrera, el resto por cuenta propia. Respecto del momento en que discontinuaron los estudios, sólo una persona lo hizo durante el Ciclo Básico Común (CBC) ${ }^{1}$, seis al principio de la carrera, seis a la mitad y tres hacia el final.

A pesar de la heterogeneidad de los entrevistados, las representaciones previas al ingreso de la carrera son similares: considerando a los 16 entrevistados de Comunicación, 14 dijeron que su idea previa al ingreso a la carrera era ser algún tipo de periodista (sea radial, gráfico, deportivo, etcétera). De las dos restantes, una empezó la carrera para hacer publicidad o comunicación institucional, y la segunda no pudo ingresar a actuación en el Instituto Universitario Nacional de Artes y decantó por Comunicación porque entendía que eso tenía relación con la capacidad de oratoria.

En este sentido, prácticamente en su totalidad dijeron que cuando estaban en el secundario pensaban que Comunicación era parecido a periodismo. Esta relativa homogeneidad relacionada con las representaciones sobre el futuro laboral que ofrecería la carrera se dio a pesar de la heterogeneidad de los entrevistados tanto en relación con la clase social, al género como al capital cultural previo:

No tenía una idea de nada. Era ir viendo sobre la marcha, no era algo específico. Tenía una idea global de que hacer Comunicación Social era ser periodista, ésa era la idea que te vaticinaban también desde la escuela, por lo menos y desde el test vocacional que hicimos: periodista (Clara, 27 años, Comunicación).

Las personas entrevistadas entraron a la carrera pensando mayoritariamente que iban a hacer periodismo, y en su totalidad lo vinculaban con saberes que denominaron "más prácticos". Aquellos casos que no discontinuaron sus estudios durante el CBC o los primeros años, siguieron sin una visión muy clara respecto de a qué se iban a dedicar. En algunos casos continuaron porque las materias les parecían interesantes, pero sin una definición clara respecto de lo que harían con esos saberes.

Si se comparan estas representaciones previas sobre la carrera con la información institucional que difunde la Facultad de Ciencias Sociales respecto del campo ocupacional que abre Comunicación, se puede observar que no coinciden en diversos aspectos. Contrariamente a la expectativa previa de hacer una carrera "más práctica", la misma Facultad especifica que la carrera de Comunicación tiene "una fuerte dosis de teoría social" en la descripción que hacen en la web y en el video institucional de la facultad, así como también se puede advertir lo mismo en el plan de estudios comparando la cantidad de materias vinculadas con análisis teórico por oposición a los talleres.

En otras palabras, toda la información institucional de la carrera y de la facultad mencionada, hace explícito que Comunicación no es (solamente) periodismo

${ }^{1}$ Es el primer año de la Universidad de Buenos Aires, con materias en común para todas las carreras y se cursa en un edificio o sede diferente al de la carrera elegida. 
ni publicidad y que la carrera no se circunscribe a una práctica de dichas ocupaciones, sino que involucra un fuerte análisis teórico, sin embargo todos los entrevistados mencionaron que se sorprendieron porque la carrera "no era lo que esperaban" (aunque no necesariamente aludan que ello fue la causa de la discontinuidad). Encontramos en la carrera de Comunicación que las dos representaciones previas más enunciadas y representativas en los relatos fueron: 1) la que asociaba Comunicación a periodismo y 2) la que asociaba la carrera a un saber práctico.

Respecto de la representación previa de que Comunicación era periodismo, en todos los casos se mencionó que ya no pensaban lo mismo, pero tampoco pudieron definir qué implica ser licenciado en Comunicación. En lo único en que coincidían al momento de definirla es en que se trata de una carrera "amplia", que involucra "un poco de distintas disciplinas" o que es "poco específica": "para mí es muy interesante. Vas a poder aprender muchas cosas, tenés que leer mucho, pero es muy poco específica" (Julia, 33 años, Comunicación).

En relación con la representación previa respecto de que esperaban una carrera más práctica, hubo después un consenso generalizado en describirla como eminentemente teórica:

Si tengo que decir una característica es que tiene mucha teoría. A veces excesiva en algunas materias porque no se termina evaluando todo lo que se da (Gustavo, 24 años, Comunicación).

En menor medida también aparecían las representaciones previas de quienes esperaban hacer la carrera de acuerdo con el plan de estudios y luego se encontraron con una carrera "larga":

Igual esta carrera era como una gran máquina de generar sensaciones de infinitud. Me acuerdo que recién arrancaba y no paraba de cruzar gente "che, ¿y vos hace cuánto?" "no, yo estoy acá hace 8 años”,

\begin{abstract}
"no, ésta la recursé, pero ahora la aprobé". No me preguntes por qué, pero todo se volvía pesado, costoso, pastoso (Agustín, 28 años, Comunicación).
\end{abstract}

Y finalmente, aparecía la indefinición respecto del futuro laboral en relación con la carrera,

[la carrera] me gustaba todavía [...] pero no dejaba de ser muy abstracto y era como que yo quería ver algo más práctico porque yo decía "bueno, esto sí está todo bárbaro, pero ¿cómo lo aplico? Se supone que quiero vivir de esto”. No me están enseñando, no sentía que me estaban formando como profesional” (Celeste, 26 años, Comunicación).

Pero las representaciones respecto del futuro laboral como algo indefinido estaban supeditadas a las otras representaciones nodales de la carrera: no había una definición clara respecto de lo que iban a trabajar porque no tenían una imagen clara de a qué apuntaba la carrera. Si la carrera formase periodistas, uno sabría que va a trabajar de periodista o que al menos va a competir en el mercado laboral de periodistas. Sin embargo, las representaciones previas respecto de Comunicación no coincidían con la experiencia estudiantil en la carrera. Considerando lo previo, observamos que las carreras con horizontes laborales más nítidos, como el caso de Ciencias Químicas, permiten una representación previa más homogénea de su perspectiva laboral pero que después no necesariamente se traduce en una experiencia deseada.

La incertidumbre respecto del posible campo laboral y en la definición de la especificidad de la disciplina es un común denominador de las disciplinas blandas según Becher, a lo que en Ciencias de la Comunicación se suma la divergencia compartida entre la representación previa respecto de lo que se va a estudiar en la carrera y la posterior experiencia estudiantil, lo cual es confirmado también por estudios previos (Ferrarós et al., 2010: 101; Carli, 2012: 144). 
Ahora bien, ¿por qué sucede esta divergencia entre las representaciones previas de los sujetos respecto de la carrera - las cuales son compartidas por todas las personas entrevistadas - y la difusión institucional de la facultad? Lo que tenemos es una representación previa compartida respecto de la carrera que es distinta a una experiencia universitaria relativamente consensuada también. Un objeto, como una carrera universitaria cualquiera que sea, se distingue como tal no por un trascendental que lo preceda (por ejemplo, su definición institucional), sino que es definido por una estructura de significados que le fueron otorgadas al objeto (Danto, 2012: 99).

En este sentido, la Facultad de Ciencias Sociales puede difundir que el campo ocupacional de la carrera de Comunicación comprende un espectro más amplio y complejo que el de un terciario en periodismo, pero el tema es que hay identificaciones en los objetos (como la identificación de Comunicación con periodismo) que fundan interpretaciones sobre dichos objetos (Danto, 2012: 57).

Las decisiones de los sujetos, especificadas en este caso por la elección de la carrera de Ciencias de la Comunicación, estuvieron mediadas por las representaciones previas respecto a ella, en tanto que esas imágenes constituyen prácticas sociales también. Los aspectos principales de Comunicación difieren sin embargo de las restantes carreras tanto en el tipo de representaciones que intervienen en modos específicos de discontinuidad como en la importancia que tienen estas representaciones en dicho proceso. Esta comparación será recuperada hacia el final del artículo.

\section{Ciencias Antropológicas}

Similar al caso de Ciencias de la Comunicación, en Ciencias Antropológicas las representaciones que operan con más fuerza también son las representaciones previas respecto de la carrera. Esto se deriva principalmente de lo observado en el trabajo de campo, dado que no encontramos referencias a trabajos sobre las representaciones previas al ingreso a la misma. El único antecedente es la ponencia presentada en el V Congreso de Antropología Social, "Un trabajo sobre las representaciones de los ingresantes a la carrera de Antropología" (Cordero et al., 1997) en donde los autores se preguntan "¿qué 'imaginan' los alumnos que estudian antropología?” y concluyen:

- El discurso con el que los alumnos racionalizan su elección [de la carrera] es relativamente homogéneo en las diferentes cohortes.

- Las formas de adjetivar descritas podrían reflejar un fuerte compromiso emocional respecto a la elección, como un rasgo caracterizador de estas respuestas.

- Podemos señalar como un aspecto significativo la vinculación recurrente de la disciplina con las culturas, el pasado, el hombre, la evolución y origen del hombre, y la investigación.

- Es interesante destacar que se referencia a la Antropología más con el estudio del pasado, que del presente o del futuro (Cordero et al., 1997: s/n).

Si bien la investigación de Cordero et al. fue realizada en 1997 en ingresantes de Antropología en la Universidad Nacional de La Plata, se observan coincidencias con los relatos de los entrevistados de la misma carrera en la UBA. Por ejemplo, Marcelo (27 años, Antropología), quien se inscribió con la idea de seguir la orientación en arqueología, menciona respecto de la elección de la carrera:

Entrevistador: ¿En qué momento elegiste Antropología y por qué?

Entrevistado: Me gustaba todo lo que era histórico, siempre estaba interesado en los artículos periodísticos de algún yacimiento arqueológico en cualquier parte del mundo, inclusive acá en Argentina. Esa parte me gustaba. Siempre mostré interés en "lo humanístico", si querés. 
Entrevistador: O sea, si vos tuvieses que describirme. ¿Qué pensabas, a los 17 años, que ibas a trabajar siendo arqueólogo?

Entrevistado: Me imaginaba que iba a estar en algún lugar excavando. [...] En algún lugar, ponele, en La Pampa, en el Norte, excavando algún yacimiento arqueológico.

Se observa la referencia a lo "histórico" y en el caso de Marcelo, la representación de estar "excavando" en "cualquier parte del mundo". En relación con los que eligieron la carrera para hacer la orientación en socio-cultural observamos:

Yo creo que pensaba que iba a estudiar a los incas y no sé, que iba a ver más poblaciones así [... para mí] la antropología era como el estudio pero no de las sociedades occidentales sino de las sociedades [...] como de sociedades más extrañas" (Viviana, 30 años, Antropología).

Nuevamente aparece la referencia al pasado, tanto en la idea de "lo antiguo" como de estudiar a poblaciones "más extrañas". Pero no es un "pasado" cualquiera, sino uno vinculado con culturas no occidentales: ello se observa en la mención de los incas como en otras alusiones. Paralelamente, otro significante fuerte que aparece en los relatos es la idea del trabajo al aire libre y la idea de viajar a lugares poco comunes, como se observa en la cita previa de Marcelo con relación a que "imaginaba que iba a estar en algún lugar excavando", pero también en los restantes entrevistados:

No recuerdo exactamente qué me imaginaba. Tenía la certeza de que iba a viajar por el mundo. Como que eso me iba a permitir viajar por el mundo con un motivo honorable, como desarrollar estudios antropológicos. Era como una justificación de viajar por el mundo" (Tomás, 29 años, Antropología).
De las ocho entrevistas realizadas a personas que discontinuaron sus estudios de Ciencias Antropológicas en la UBA, todas relataron que la idea que tenían sobre la carrera al momento de anotarse estaba relacionada con la idea de cultura y con el pasado (o "lo antiguo"). Menos en dos casos, en donde no fue mencionado, todos asociaban al antropólogo con viajes a distintos lugares.

Esta gran homogeneidad en las representaciones previas de lo que significaba para los entrevistados ser antropólogo sucede a pesar de la heterogeneidad de los entrevistados: cuatro varones y cuatro mujeres; tres dejaron a mitad de la carrera, otros tres hacia el final (a una sólo le faltaba la tesis de grado) y los restantes en los inicios de la carrera; tres se criaron y cursaron viviendo en Capital Federal, una se crió en Mendoza y vino a terminar el secundario en la Ciudad Autónoma de Buenos Aires (CABA), dos crecieron en Gran Buenos Aires (el área metropolitana que rodea a la ciudad) y cursaron viviendo a más de una hora y media de viaje de la facultad y los dos restantes eran de distintas provincias y se mudaron a CABA para estudiar Ciencias Antropológicas.

Considerando la auto-afiliación de clase social, había tres de clase media-baja, cuatro de clase media y uno de clase alta. Tres casos eran de padres sin título universitario: un entrevistado sus padres tenían título terciario, en otro caso universitario no finalizado y en otro eran egresados del secundario. Finalmente, las trayectorias pos-abandono: dos continuaron carreras universitarias en instituciones privadas, cuatro se dedican a actividades vinculadas con hobbies mientras cursaban (artesanías, fotografía, yoga y cine) y los dos restantes trabajan de empleados.

Como se puede observar, se trata de un grupo relativamente heterogéneo pero las representaciones sobre la carrera y la universidad muestran gran homogeneidad. Lo mismo se observa en las representaciones acerca del futuro laboral como antropólogo y las opciones que habilita la carrera según los relatos de los entrevistados. En ese aspecto, ninguno podía 
decir con certeza a qué se iba a dedicar, pero asociaban la carrera a significantes que les resultaban atractivos, como "viajar", "cultura", entre otros ya mencionados. La representación de a qué se dedica un antropólogo se realiza recién en los primeros años de la carrera, y se refuerza en el tránsito por ésta:

Nunca nos hablaron del investigar ni nada por el estilo [...] Podías saberlo, pero no lo sabías. Podías tenerlo de nombre, pero no sabías específicamente como era toda la carrera de investigador, qué tenías que hacer para ser investigador, qué hacía el investigador. Todos esos manejos más internos, no (Marcelo, 27 años, Antropología).

Todos los entrevistados mencionaron que las representaciones sobre el futuro laboral que fueron construyendo durante el transcurso de la carrera eran las de docencia e investigación. Según los propios relatos, tanto los compañeros como ellos mismos apuntaban a una de esas salidas laborales:

En el imaginario de los estudiantes no hay muchos destinos para el antropólogo. No los hay. Te dedicás a la docencia haciendo lo mismo que están haciendo todos los antropólogos, o sea, dar clases de antropología para los que van a ser antropólogos y van a hacer lo mismo. [...] No sé cuánta aplicación de la carrera tenés más que estudiar y seguir investigando. Y yo creo que eso era bastante desentusiasmante también (Inés, 33 años, Antropología).

En relación con este punto las entrevistas daban cuenta de dos elementos importantes: por un lado, la caracterización de la carrera basada en la experiencia de cursada como eminentemente teórica o con poca salida al campo, lo cual entraba en conflicto con la representación previa del viaje. Por otro lado, aun frente a la heterogeneidad de entrevistados existe consenso respecto de cómo se representaban el futuro laboral: el antropólogo se dedica a la docencia o a la investigación académica. Sin embargo, ese consenso no es previo a la inscripción a la carrera, sino que se construye durante el tránsito por la misma. Dos casos de los ocho manifestaron no tener claro a qué se dedicaba un licenciado en Antropología, sabían que hacían "investigación", pero no sabían qué implicaba ello:

No pude nunca vislumbrar, mientras estaba cursando, de qué se trataba ser antropólogo. No tuve idea.

Eso me la bajó. (Lorena, 29 años, Antropología).

Una vez aceptado ese discurso compartido sobre el futuro laboral del antropólogo (real o no, pero compartido), los entrevistados se enfrentan a las preguntas ¿podré lograr ser investigador o docente? Y sobre todo ¿eso es lo que deseo? Había un consenso de que la salida privilegiada del antropólogo es en investigación y docencia, pero ese trabajo no era lo que esperaban o les desilusionó.

Paralelamente, el ingreso al mundo de la investigación es complejo e involucra no sólo aspectos académicos (como tener un buen promedio), sino saber desde el principio de la carrera las tácticas (De Certeau, 2000) para tener un recorrido exitoso en los términos que valora la academia, como por ejemplo saber que es "clave estar en grupos de investigación" o saber que "el promedio es importante". Estos saberes que "la UBA no te facilita nunca" tal como fueron descritos por otro entrevistado en una cita anterior (Marcelo, 27 años, Antropología).

Resumidamente, observamos que los significantes previos asociados a la carrera de Ciencias Antropológicas tienen un peso importante en la elección de la carrera. Estos significantes eran predominantemente "cultura", "viaje", "pasado" (o lo "antiguo") y "sociedades no-occidentales".

Considerando ello, podría pensarse como un caso similar al de Comunicación en donde el peso de las representaciones previas al ingreso incide en la discontinuidad cuando esas representaciones 
no se condicen con la experiencia estudiantil. Sin embargo, éste no es el caso de Ciencias Antropológicas. Si bien los entrevistados mencionan que la Antropología "no es sólo" el estudio de sociedades no occidentales, esas diferencias con respecto a sus representaciones previas no son motivo de conflicto en los relatos.

Hay otros aspectos que sí implican representaciones previas en colisión con la experiencia de cursada. Por un lado, la predominancia del perfil sociocultural en la formación, lo cual termina siendo conflictivo para quienes querían tener una formación arqueológica, como se observa en los relatos:

yo sigo enamorada de la Arqueología pero en el tronco común hay una sola materia de Arqueología. El resto es todo Antropología social (Alejandra, 33 años, Antropología).

Un segundo aspecto de conflicto entre las representaciones previas y la experiencia de cursada refiere al poco trabajo de campo durante la cursada y la caracterización de la carrera como eminentemente teórica (por oposición, si se quiere, a la expectativa de "viajar"). La descripción de Ciencias Antropológicas como una carrera "teórica" aparece en todos los relatos sobre todo por la expectativa previa en encontrar otra cosa.

Sin embargo, la representación que más termina operando en la discontinuidad de los estudios es la que asocia la salida laboral del antropólogo con la docencia y la investigación. Tal como se mencionó previamente, éstos no necesariamente son los modos predominantes de ejercicio profesional del licenciado en Ciencias Antropológicas, pero sí son percibidos como tales.

A diferencia del caso de Ciencias de la Comunicación, donde las representaciones sobre el futuro laboral eran más inciertas, el horizonte porvenir se representa en Ciencias Antropológicas de una manera más compartida y homogénea, pero que no necesariamente se traduce en la perspectiva deseada, concebida como posible o incluso la representación respecto de lo que implicaba "ser investigador" no fue la misma al principio de la carrera que hacia el final. Como se mencionará más adelante, esto guarda una estrecha relación con la carrera de Ciencias Químicas.

\section{Ciencias químicas}

Acerca de Ciencias químicas, no encontramos un estudio previo que hiciera referencia a las representaciones sociales sobre estudiar esa carrera en la universidad. Sin embargo, descubrimos investigaciones que estudian las representaciones sociales acerca de la ciencia y los científicos, entre ellos los químicos. Legarralde et al. (2009) presentaron un estudio sobre las representaciones que estudiantes de secundaria de un colegio de Chascomús tenían de los científicos. Al respecto, algunas de las conclusiones mencionadas son:

- El $89 \%$ de los encuestados esquematizaron que los científicos son personas de sexo masculino [...] cuya consecuencia es una menor representación femenina en la investigación científica.

- La mayoría esquematiza a un científico preferentemente relacionado con la Química, siempre en el interior de un laboratorio en el cual hay una mesa con libros, microscopios y materiales de vidrio en los que se mezclan sustancias. Siempre la actividad se realiza en soledad.

- En cuanto a la personalidad del científico, las respuestas señalan a una persona solitaria, rara, seria, con una inteligencia superior al resto de la sociedad, el cual, por la actividad que desarrolla, se pasa todo el día estudiando, por lo cual no posee vida social ni familiar (Legarralde et al. 2009: pp. 170-175).

Los autores encontraron que las representaciones de los estudiantes de secundaria sobre los científicos generalmente están asociadas a la imagen del 
químico en el laboratorio, pero que además lo caracterizan como varón, inteligente y "sin vida social" ni familiar. Es interesante destacar, como mencionamos previamente, que la representación del científico en este caso y del químico en particular se construye no a partir de conceptos, sino a partir de materialidades. En este caso: la "mesa con libros, microscopios y materiales de vidrio en los que se mezclan sustancias".

La tesis de maestría de Tilde Vanina Daraio "Las representaciones sociales y las trayectorias científicas. Un estudio de caso con estudiantes y graduados de carreras de ciencias exactas y naturales", confirma esta asociación entre el científico y el químico: "En principio, la computación y la geología que parecen circular alejadas de lo que sería la 'ciencia' dentro de la academia, por sus modalidades de investigación alejadas del clásico laboratorio químico, son también profesiones que circulan socialmente como aplicadas asociadas a la industria y a la empresa" (Daraio, 2014: 214).

$\mathrm{Al}$ mismo tiempo, menciona la fuerte asociación entre la representación del "ser químico" y la materialidad del laboratorio. En nuestro estudio, recuperamos las representaciones previas para el caso de la carrera de Ciencias Químicas y observamos también la preeminencia del ideario de "el químico como científico", del "trabajo en el laboratorio" y la vinculación metonímica entre científico y profesión distinguida. A partir de una primera entrada al campo, observábamos cómo la asociación "científico" y "químico" invisibilizaban la posibilidad de imaginar salidas profesionales o más orientadas al mercado privado. Como veremos más adelante, esto es manifestado de manera conflictiva por algunos entrevistados.

Se entrevistaron 11 personas de la carrera de Química: tres varones y ocho mujeres. Tres personas vivieron solas durante la cursada o gran parte de ella y ocho siempre con sus padres. Seis vivían a más de una hora de viaje de la sede donde se cursaba la carrera, el resto a menor distancia: cinco vivían en el GBA, el resto eran de Capital Federal, nadie venía de otra provincia. Dos de ellos discontinuaron en el CBC, cinco al inicio de la carrera, tres a la mitad, y uno cerca de finalizar.

Considerando la auto-afiliación de clase, una persona se definió de clase baja, cinco de clase mediabaja, dos de clase media y dos de clase media-alta. Respecto de las trayectorias pos-abandono, cinco continuaron sus estudios en un terciario, cuatro en otras universidades, los dos restantes no retomaron ningún tipo de estudios. Cuatro de ellos trabajan actualmente en relación con la Química, tres están estudiando con el objetivo de trabajar en algo vinculado con dicha disciplina, dos cambiaron totalmente de área y los dos restantes no trabajan ni estudian.

En este grupo lo que se pudo observar es que no se representaban al químico, sino que representaban la carrera a través de una práctica y una materialidad: el laboratorio.

Entrevistada: la idea de científico la tenía en mi cabeza. No es la idea que tengo hoy y con la cual concuerdo...

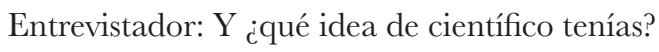

Entrevistada: (...) era como algo muy de "bueno, voy a estudiar yo sola en un laboratorio". Qué se yo, la idea de científico que tiene todo el mundo. La mayoría de la gente: yo sola con mi guardapolvo estudiando algo que le puede importar a alguien (Paloma, 26 años, Química).

La entrevistada narra que no sabía exactamente a qué se iba a dedicar, o qué iba a investigar en específico, pero le gustaba la idea de "científica con guardapolvo blanco" quien investiga algo que "quizás impactaría en el mundo". Tal como se menciona en el estudio de Legarralde et al. (2009) los significantes que aparecen son el laboratorio, la soledad y la inteligencia.

Uno de los conflictos entre los entrevistados de Química está entre las representaciones previas que tienen sobre el trabajo del científico y las tareas 
que efectivamente se realizan en el laboratorio. Estudios previos, como Vida en el laboratorio de Latour y Woolgar (1995), dan cuenta que el trabajo en el laboratorio implica una serie de prácticas rutinizadas, relaciones de poder en el marco de una estructura jerárquica, distribución de tareas (y de reconocimientos) en relación con esas jerarquías, y mucho tiempo dedicado a la elaboración de informes técnicos (Latour y Woolgar, 1995: 58-64).

La "vida en el laboratorio", usando la expresión de Latour, es en principio invisible para quien no participa en ella. La investigación y la práctica del químico eran representadas antes del ingreso a la carrera con las imágenes de "los tubos de ensayo" y "al lado de un laboratorio", a los cuales asociaban al significante "investigación". Sin embargo, la idea previa que tenían respecto de lo que implicaba hacer investigación fue cambiando a lo largo de la carrera. Esto tomando incluso entrevistados cuyos padres estudiaron Ciencias Químicas en la UBA:

\section{Entrevistador: (...) ¿qué sabías de la carrera?}

Entrevistado: Sabía que estaba más enfocada a investigación.

Entrevistador: ¿Entendías lo que era "investigación" en ese momento?

Entrevistado: Eso por ahí no tanto. No. O sea, por ahí podía llegar a entender a alguien que trabajaba en la industria o en un laboratorio, pero por ahí en ese momento no te podría haber llegado a definir bien cuáles eran esas diferencias (Adrián, 33 años, Química).

Encontramos entonces el peso en las representaciones previas de los significantes "laboratorio" e "investigación", además de las asociaciones con respecto a la experiencia estudiantil del secundario: a diferencia de las restantes carreras, en Ciencias Químicas 10 de los 11 entrevistados provenían de escuelas técnicas o con orientación en Ciencias Naturales.

Con respecto a las representaciones que fueron construyendo a lo largo de la carrera, Ciencias Químicas pasa de "demandante" a "difícil", pero esos son significantes que asocian luego de haber empezado la cursada. Previo al ingreso todos los entrevistados imaginaban a la carrera de Ciencias Químicas como demandante pero realizable; solo tres mencionan que "la verdad es que sabía que iba a ser algo complicado" (Valeria, 25 años), pero nueve de los 11 entrevistados mencionan que como les iba bien en el secundario no se imaginaban que les resultaría difícil de sobrellevar.

A lo largo de la cursada, hay una transformación entre representarse a la carrera como "demandante" a "difícil". La dificultad la asocian principalmente a los contenidos de las materias, aunque también en algunos casos mencionan elementos como la organización horaria o el modo de dar clases de los docentes que se suman a la dificultad de los contenidos.

En los relatos aparecen elementos que relacionan a las representaciones previas con la cultura institucional, particularmente en lo referido a la organización horaria de la carrera con otras actividades y al rol del docente, lo que Remedi denomina una "cultura de la enseñanza basada en valores, hábitos y formas de hacer las cosas" (Remedi, 2004: 45).

Comparando los estudios previos que asociaban al químico con el laboratorio y lo "caracterizan como un varón inteligente y sin vida social ni familiar", se observó que las personas entrevistadas se representaban la carrera a partir de la idea de laboratorio, pero que también lo vinculaban al significante "investigación".

Este último elemento es clave para entender los procesos de discontinuidad en dicha carrera, puesto que se observó una modificación respecto a la representación que tenían sobre "el mundo de la investigación científica" en Argentina. Recordemos que el significante "investigación" es un significante nodal en la representación sobre el futuro laboral de los químicos. En este sentido, luego de discontinuar los estudios universitarios, las personas entrevistadas siguen 
pensando que el horizonte para el que mejor les prepara la carrera es para la investigación académica, pero la representación sobre lo que implica "hacer investigación" ya no es la misma comparativamente con la representación que tenían en el ingreso.

Luego de discontinuar los estudios universitarios, un solo entrevistado dijo que todavía le interesaba la investigación. Paralelamente, cinco de ellos manifestaron que les gustaría trabajar en laboratorios o ya estaban trabajando en uno al momento de la entrevista, aunque más vinculados con la industria (para la cual, en muchos casos no les exigen tener el título universitario). Por otro lado, dos entrevistadas buscaron formarse en el ámbito de la docencia en química y finalmente tres entrevistados se desvincularon de la química por completo.

Lo que se observó entre los estudiantes que discontinuaron sus estudios es una desilusión respecto al mundo de la investigación académica, principalmente por lo que describen como un ambiente competitivo e individualista, y segundo porque apunta más a la producción de publicaciones que no representan, en los relatos de las personas entrevistadas, su ideal de investigador. En otras palabras: la imagen del científico se vincula más con el laboratorio que con la producción de papers, a la cual ven como un corolario del modo de producción científica actual.

Estas modificaciones respecto de la representación previa al ingreso que tenían sobre "hacer investigación", y que fueron producto de su experiencia estudiantil, no puede ser tomado como única causal de la discontinuidad de los estudios universitarios, pero si explica en parte la lógica argumental a partir de la cual los entrevistados decidieron dejar la carrera.

Por otro lado, si bien no hubo referencias a que para estudiar la carrera haya que ser particularmente inteligente, las representaciones previas daban cuenta de que estudiar Ciencias Químicas era "demandante", pero la demanda refería principalmente al esfuerzo y a los tiempos de estudio que imaginaban que iban a tener que dedicar. Sin embargo, la caracterización posterior la definía como "difícil" en términos de los contenidos, pero principalmente por obstáculos de la cultura institucional (principalmente referidos al modo compartido de dar clases de los docentes, como a las dificultades horarias y a la imposibilidad de congeniar la facultad con otras actividades). Respecto de la representación previa que asociaba a la carrera como "solitaria", no encontramos que ello haya representado algún conflicto como sí lo hizo en Ingeniería en Informática.

\section{Ingeniería en Informática}

En el ya citado informe "Las representaciones sociales de los aspirantes a ingresar a la UBA" (Canessa et al., 2002) se realiza un breve análisis de las representaciones previas del conjunto de las carreras vinculadas a la Informática: Análisis en Sistemas e Ingeniería en Informática en la Facultad de Ingeniería de la UBA, Ciencias de la Computación en Exactas y la licenciatura en Sistemas de Información en la Facultad de Ciencias Económicas. Dicho informe agrupó el análisis de las carreras mencionadas por "la dificultad que muestran los estudiantes para reconocer con claridad qué es lo específico de cada una de ellas. Las diferencias en los planes de estudio se desdibujan en los campos ocupacionales, campos muy próximos que en algunas carreras llegan a superponerse" (2002: s/n).

Las conclusiones del informe refieren a que el núcleo de representaciones en común presentes en los estudiantes que eligen dichas carreras se concentran en dos cuestiones centrales: 1) la asociación con el uso de computadoras sin especificar cómo se desarrolla ese uso y 2) la certeza de una salida laboral asegurada (2002: s/n).

El informe también habla de representaciones menos significativas como "el encantamiento que parecen ejercer estas carreras sobre los jóvenes remiten a un conocimiento sin límites y que, por otra parte, permite saberlo todo de un mundo tecnológico y sofisticado" (Canessa et al., 2002: s/n). 
En nuestro caso, se entrevistaron ocho personas que discontinuaron los estudios en Ingeniería en Informática de los cuales dos son mujeres y seis varones; dos egresaron de colegios universitarios, ${ }^{2}$ tres de bachilleres y tres de colegios técnicos; cuatro dejaron hacia el final de la carrera (ya habiendo empezado la orientación final), dos al principio y dos habiendo pasado la mitad de las materias del plan de estudios; dos eran originarios de pueblos chicos del interior y vinieron a Buenos Aires a estudiar, tres vivían con sus familias en el GBA y los tres restantes en CABA.

Coincidentemente con el informe de Canessa et al., los entrevistados se representaban la carrera a partir de la asociación con una materialidad: la computadora. Todos los entrevistados mencionaron que les gustaba usar la computadora, sea para jugar o haciendo algún tipo de programación básica. Por ejemplo, el siguiente entrevistado relata:

no sé si me acuerdo digamos bien qué iba a hacer. Pero me parece que ya tenía una cierta atracción por las computadoras [...] Realmente por ahí no tenía mucha idea de cómo era el trabajo. Pero bueno, tampoco es muy distinto a lo que creo que la mayoría de la gente se imagina: estar frente a la computadora (Diego, 27 años, Informática).

Otras asociaciones previas con respecto a la carrera son la asociación entre Informática y "la tecnología”, pero la representación predominante es su asociación con el objeto computadora. En este punto se asemeja al caso de Química con el laboratorio, con la diferencia de que el objeto laboratorio es figurado como más "atemporal", mientras que la computadora es vista como "la novedad".

En relación con la representación respecto de la posible salida laboral, en Ingeniería en Informática emerge la representación de que se iban a dedicar a "programar", aunque seis de los entrevistados mencionaron que cuando se anotaron a la carrera no estaban seguros de todo lo que implicaba programar y que la carrera no te prepara "sólo para eso". En este punto, también se asemeja al caso de Ciencias Químicas y su asociación a "la investigación".

Asimismo, en coincidencia con el informe de Cannesa et al., observamos la representación previa de una salida laboral rápida y con buen salario. Esa idea de que hay mucha oferta laboral con salarios buenos para alguien que está estudiando, se ve confirmada en la experiencia estudiantil:

a mí me ofrecieron trabajo tres veces y no lo acepté pero digamos que te está hablando alguien que hizo sólo dos años y ya puede conseguir trabajo, o sea: hay una demanda, que te llama a la deserción también [...] te va a pagar un sueldo muy atractivo para alguien que está empezando la facultad [...] hay gente que prefiere no trabajar, pero al mismo tiempo recibirse sin trabajar también está mal visto (Ricardo, 24 años, Informática).

De esta conversación y otras similares decantan dos cuestiones: la primera es que hay una gran demanda por parte del mercado laboral de estudiantes de Informática con sueldos atractivos según los relatos de los estudiantes. Este dato encuentra relación con estudios previos como los de Panaia (2013: 46) quien menciona respecto de las Ingenierías en general que hay una "proporción significativa de estudiantes que estabilizan su posición accediendo a un contrato de dependencia, aun antes de lograr un título de ingenieros".

El segundo dato significativo que aparece en distintos relatos refiere a que "recibirse sin trabajar también está mal visto". Esto coincide con la caracterización de Informática como una carrera de perfil profesional en la cual el tipo de conocimiento privilegiado es aquel aplicado al trabajo.

\footnotetext{
${ }^{2}$ Con colegios universitarios nos referimos a las escuelas de educación media de dependencia universitaria.
} 
Entrevistador: ¿Y por qué decidiste empezar a trabajar?

Entrevistada: Y porque me pareció que ya había avanzado un poco más en la carrera y que tampoco me iba a servir recibirme, tener un título de ingeniera y no tener nada de experiencia (Cristina, 32 años, Informática).

Esta relación entre la carrera universitaria y el mercado de trabajo fue descrita por uno de los informantes clave como "un arma de doble filo" en tanto que, según su percepción, convoca a muchos estudiantes de secundario a inscribirse a la carrera (por el hecho de que ofrece una salida laboral rápida y lucrativa) pero al mismo tiempo genera que muchos estudiantes no terminen los estudios porque el mercado no pide un título. Las entrevistas dan cuenta además de un dato adicional en esta relación entre mercado de trabajo, ejercicio profesional y carrera universitaria: el hecho de que hay una formación específica que se realiza en "la experiencia laboral" y no en la facultad:

realmente para conseguir a empezar a laburar podés empezar así en primer año y segundo si te fijás. De hecho, no es recomendable terminar la carrera y recién ahí ponerte a buscar trabajo, porque suele pasar que en esos casos están muy fuera de lo que se hace laboralmente. [...] pasa también un poco eso: muchas de las cosas que ves en la facultad no son $[\ldots]$ o muchas cosas que son después del laburo no las ves en la facultad. Eso pasa (Diego, 27 años, Informática).

Es decir, hay una percepción de que hay dos tipos de conocimientos: el que se genera en la facultad y el del mundo laboral, que son diferenciados, que tienen sus especificidades y que, en el marco de esta disciplina, si bien no se desestima el conocimiento universitario, el segundo es más valorado. Esa jerarquía de los tipos de conocimiento (el universitario y el del mundo del trabajo) es fortalecida por la representación del conocimiento universitario como "anticuado":

Entrevistado: Está bastante atrasado lo que es la UBA en cuanto a eso. No sé lo que estarán usando ahora pero en ese momento en cuanto a programación estructurada, por ejemplo, usaban [el lenguaje de programación llamado] Pascal. No sé si lo seguirán usando.

Entrevistador: Yo vi en los grupos de Facebook varios estudiantes quejándose del Pascal...

Entrevistado: Ah, entonces siguen usando lo mismo. Eso ya está re obsoleto [...] bueno, por eso te digo que te sirve muchísimo la experiencia laboral, porque si te vas a quedar con eso estás al horno cuando quieras empezar a trabajar (Cristina, 32 años, Informática).

Esta representación del conocimiento que se genera en la universidad como "anticuada" o "prehistórica" colabora en fortalecer la distinción entre un "mundo académico" y un "mundo real":

Un ejemplo con materias de programación: el lenguaje de programación que eligen era un lenguaje que no se usa en los ámbitos laborales [...] ¿por qué no me enseñás un lenguaje que sí exista en el mundo real? (Claudio, 32 años, Informática).

Respecto de este punto, autoridades de la carrera e incluso algunos entrevistados mencionaron que usar un lenguaje de programación caracterizado como "anticuado" no es un problema por el tipo de lenguaje en sí, porque los fundamentos de un lenguaje de programación por más nuevo o viejo que sea se mantienen. Todas las personas entrevistadas coinciden con esa lectura, sin embargo, a pesar de que todas las personas entrevistadas entienden que la estructura de un conocimiento se mantiene más allá de que el lenguaje de programación sea más 
nuevo o viejo, también mencionan que el uso de un lenguaje viejo resulta poco motivante:

Por ejemplo, siguen con Pascal. Es algo prehistórico. Meté algo más nuevo y hacele programar un videojuego. Es lo que le atrapa a todo el mundo. Entonces no un "hacete una base de datos de un hotel”. No. ¡Hacé un videojuego! (Karina, 29 años, Informática).

Esta relación entre mercado de trabajo del informático, representaciones respecto de lo (in)necesario que es el título para conseguir un buen trabajo, la cultura institucional de perfil profesional, la representación de que hay dos tipos de conocimientos: el de la facultad y el del mundo laboral ("real"); y la percepción de que ciertos conocimientos de la carrera son "anticuados" y "poco motivantes", genera modos específicos de discontinuidad de los estudios.

Sumado al vínculo mundo del trabajo y universidad, hay que destacar dos representaciones previas fuertes de las entrevistas realizadas y que no aparecen en el estudio de Canessa et al.. Primero, está el hecho de que los entrevistados eligieron la carrera de Informática por sobre las tres restantes vinculadas al mundo de la computación que ofrece la UBA (las ya mencionadas de Ciencias de la computación en Exactas, Análisis de Sistemas en la Facultad de Ingeniería y Sistemas de información en Económicas) por la preferencia de tener el título de ingeniería. Este elemento es central porque los entrevistados le atribuyen a ingeniería en tanto que título una jerarquía mayor que licenciatura. En este sentido, cuatro entrevistados mencionaron que entre la oferta de carreras vinculadas "a la computación", eligieron Informática porque les ofrecía un título de ingeniero.

Entrevistador: Pero en ese momento, cuando dijiste "bueno, hay tres carreras", ¿por qué la Facultad de Ingeniería?, ¿qué pensaste en ese momento?

Entrevistado: Mi tío era ingeniero y me gustaba la idea del título de ingeniero. Las otras no eran título de ingeniero: la de Exactas y Económicas eran licenciados. Me gustaba el título de ingeniero, de hecho me meto en ingeniería sin saber toda la matemática que tenía, ni en todo el quilombo que me iba a meter (Juan, 33 años, Informática).

La segunda representación que observamos en las entrevistas y que no aparece en el informe de Canessa et al., es la idea de Ingeniería en Informática como una profesión solitaria:

Dije: "voy a elegir esto porque yo no soy muy sociable y la realidad es que no quiero lidiar con gente porque es un quilombo y qué se yo". Entonces lo que dije es "elijo esto y voy a estar sola y tranquila y laburo con computadoras" (Karina, 29 años, Informática).

Las personas entrevistadas se veían a sí mismas trabajando en soledad y lo valoraban positivamente lo cual alude a la dimensión social o individual de la experiencia estudiantil. Sin embargo, la experiencia de cursada fue distinta en el sentido en que, primero, les exigía mucho trabajo en grupo. En las materias más avanzadas, hacer un programa no es algo que se pueda hacer en soledad, en realidad se mencionan materias en las que tienen que conformar grupos de hasta 12 personas.

Segundo, está lo que varios entrevistados denominaron como "habilidades blandas", que definen como la capacidad de interpretar bien a los posibles clientes, traducirlo a un lenguaje informático y generar empatía. Una vez que conocen la práctica profesional, saben que tienen que interactuar con clientes y colegas y que la profesión no es en soledad como se la representaban.

Encontramos también distintos tipos de representaciones que entran en juego en la discontinuidad de los estudios. La más destacable es la percepción de que la carrera ofrece conocimientos anticuados y la distinción de dos mundos: el mundo universitario 
y el mundo real o laboral. Según los relatos de los entrevistados, la experiencia universitaria no alcanza para salir al mundo real y se asocia al conocimiento generado en la universidad como anticuado. Finalmente, hay otras representaciones que por sí solas no colaboran en el proceso de discontinuidad, pero que pueden serlo en su articulación con otras.

\section{Algunos cruces entre carreras y conclusiones}

Si retomamos la primera tabla del artículo, donde se recuperan distintos tipos de representaciones que podían operar en la discontinuidad de los estudios, nos encontramos con las representaciones en cada carrera anotadas en la tabla 4.

Algunas primeras observaciones que se pueden hacer a partir de la tabla pueden dar cuenta de que en Ciencias de la Comunicación la mayoría de las representaciones que inciden en la discontinuidad de los estudios son debido a que las representaciones previas chocan con la experiencia de cursada: esperaban encontrar algo como periodismo, más práctico, con posibilidad de terminarla de acuerdo con el plan de estudios y con una salida laboral más clara, pero sin embargo durante el paso por la universidad no encontraron nada de ello.

Tabla 4. Tipos de representaciones por carrera analizada

\begin{tabular}{|c|c|c|c|}
\hline Carreras & 1. Representaciones en colisión & $\begin{array}{l}\text { 2. Representaciones con nuevo sentido } \\
\text { otorgado }\end{array}$ & 3. Representaciones mantenidas \\
\hline \multirow{4}{*}{ Comunicación } & $\begin{array}{l}\text { Comunicación es igual a periodismo } \\
\text { (o publicidad) }\end{array}$ & Formación generalista & Poca salida laboral \\
\hline & Carrera muy larga & & \\
\hline & Poco práctica, muy teórica & & \\
\hline & Horizontes laborales difusos & & \\
\hline \multirow{3}{*}{ Antropología } & $\begin{array}{l}\text { Asociada al estudio de sociedades } \\
\text { antiguas no occidentales }\end{array}$ & De mucha lectura y exceso de teoría & Poca salida laboral \\
\hline & Lugares exóticos o no convencionales & $\begin{array}{l}\text { Modificaciones respecto de lo que } \\
\text { implica "ser investigador" }\end{array}$ & \\
\hline & & $\begin{array}{l}\text { Horizontes laborales nítidos pero escasos } \\
\text { y de difícil acceso } \\
\text { (investigación y docencia) }\end{array}$ & \\
\hline \multirow{3}{*}{ Química } & & $\begin{array}{l}\text { Concepción de lo demandante que es la } \\
\text { carrera }\end{array}$ & Salida laboral nítida \\
\hline & & $\begin{array}{l}\text { Modificaciones respecto de lo que } \\
\text { implica "ser investigador" }\end{array}$ & \\
\hline & & $\begin{array}{l}\text { Investigar en el siglo Xxı no es igual a la } \\
\text { idea que tenían respecto de la idea de } \\
\text { "ser químico" }\end{array}$ & \\
\hline \multirow[b]{2}{*}{ Informática } & Ser informático no es sólo programar & & El mundo académico vs. el mundo real \\
\hline & $\begin{array}{l}\text { La idea de un trabajo solitario que no } \\
\text { es tal }\end{array}$ & & Mucha salida laboral y buenos sueldos \\
\hline
\end{tabular}

Fuente: elaboración propia. 
Un caso totalmente diferente es el de Ciencias Químicas, en donde las personas entrevistadas se encontraron con todo aquello que esperaban: una carrera caracterizada como posiblemente "demandante", orientada a la investigación y donde ser químico estaba vinculado más a la vida en el laboratorio. Sin embargo, esperaban otra cosa respecto de lo que implicaba investigar, respecto de en qué aspecto les iba a demandar la carrera, o de lo que implicaba ser químico. Por ejemplo, en relación con la idea de investigar, esperaban algo más asociado a "descubrir cosas" o sin una referencia clara, y luego del paso por la universidad empezaron a caracterizar a "la investigación" con lo que describen como una competencia por quién escribe más papers. En relación con lo que les iba a demandar la carrera, esperaban algo más relacionado con un desafio intelectual, cuando en la experiencia universitaria la demanda vino por el lado de la organización de los tiempos y los horarios.

En Antropología e Informática está más repartida su distribución entre los tipos de representaciones. Antropología se divide por un lado entre las representaciones previas que entran en conflicto con la experiencia estudiantil (como en el caso de Comunicación): esperaban investigar sociedades antiguas y realizar más trabajos de campo (que en general se asocia con viajar a lugares no convencionales). Ninguna sucede. Por otro lado, como en el caso de Química, encontramos representaciones sobre elementos que los entrevistados esperaban encontrar en la carrera pero de manera distinta: es el caso de lo que esperaban que fuese la experiencia de investigar, el modo de acceso a las fuentes laborales posibles (investigación y docencia) y la carga de lectura.

Informática por su parte se divide en representaciones que entran en conflicto con la experiencia universitaria, principalmente la idea de que iban a tener un trabajo solitario y que la carrera se reduce a programar y usar la computadora. También encontramos una serie de representaciones previas que se confirman en el paso por la universidad sin ningún tipo de modificación (las representaciones mantenidas), pero que aun así intervienen en los procesos de discontinuidad de los estudios: la principal de ellas es la amplia salida laboral y los buenos salarios que, según las palabras de uno de los entrevistados, "llama a la deserción". El modo de caracterizar las representaciones está configurado en términos dicotómicos: "mundo académico" versus "mundo real", en donde la academia es caracterizada como lo antiguo u obsoleto, mientras que el mundo laboral como el acceso a lo nuevo.

Finalmente, vale mencionar que Ingeniería en Informática sirve como contraejemplo de muchos de los presupuestos asumidos en las investigaciones sobre abandono universitario, particularmente en los estudios econométricos que asocian la elección y permanencia en una carrera en función de una mayor y mejor salida laboral (Santos Sharpe y Carli, 2016: 18-19). Esto no necesariamente es así como lo demuestra este caso: la buena salida laboral en Informática no colabora con la conclusión de la carrera; tampoco una mayor sociabilidad entre pares necesariamente colabora en la permanencia.

En resumen, identificamos que las principales representaciones están asociadas a:

- La relación mundo laboral y carrera universitaria. Ya sea a partir de la idea de que "no es necesario un título para trabajar" (Informática) o que la carrera no los forma para un saber específico (Comunicación); o que hay horizontes laborales más nítidos (Química) o más inciertos (Comunicación); orientada a la investigación y la vida académica (Antropológicas y Químicas) u orientada al mercado con o sin salida laboral precisa. De esta manera, la relación mundo del trabajo y carrera universitaria es crucial para entender la discontinuidad de los estudios.

- La demanda de recursos que supone la carrera. Se observa que hay demandas por parte las carreras que las personas entrevistadas ya esperan en 
función de sus representaciones previas respecto de la misma (como tener conocimiento de matemática para Informática), pero hay otros recursos que les demanda la carrera con los que no esperaban y que son descritos como datos objetivos del desgaste o de la discontinuidad de los estudios (el más evidente: el tiempo que les demanda dentro de la facultad y la imposibilidad de realizar otras actividades).

- La experiencia estudiantil. La experiencia de estar haciendo una carrera que se representan como "eminentemente teórica", "muy difícil", "demasiado amplia" termina orientando las decisiones de discontinuidad. También en relación con las formas de sociabilidad entre pares (es un ambiente "muy competitivo", "muy machista", "carrera solitaria") y con los docentes ("buscan cagarte", "son investigadores, no docentes").

A modo de conclusión señalamos, primero, que una misma representación puede tener distintas consecuencias en función de con qué se articula. En segundo lugar, una misma representación puede tener un efecto en un momento de la carrera y otro totalmente distinto en un momento posterior (porque

\section{Referencias}

Becher, T. (2001), Tribus y territorios académicos. La indagación intelectualy las culturas de las disciplinas, Barcelona, Gedisa.

Bertaux, D. (1999), "El enfoque biográfico: su validez metodológica, sus potencialidades“, Proposiciones, 29, pp. 1-23.

Boyatzis, R. (1998), Transforming qualitative information. The thematic analysis and code development, Thousands Oaks, Sage.

Canessa, G., A. Cibeira, A. M. Arregui, L. Déboli, L. Ferrari, M.Jozami y Y. Plástina (2002), Las representaciones sociales de los aspirantes a ingresar a la UBA. La universidad, el CBC y las carreras, Buenos Aires, Departamento de Orientación Vocacional CBC, UBA. se articula con experiencias distintas). O simplemente cambiar en su conceptualización (como el caso de "investigación" en Química y Ciencias Antropológicas).

Un tercer aspecto que identificamos es que elementos tradicionalmente considerados como "positivos" o que generan mayor permanencia no necesariamente facilitan la permanencia en todas las carreras (los ya mencionados "contraejemplos" de la carrera de Informática).

En algunos casos, observamos cómo la construcción de los ideales de graduado o profesional sobre la base de representaciones previas por parte de las personas entrevistadas luego se confronta con la experiencia estudiantil. En muchos casos, la confrontación deviene en modificaciones respecto del proyecto de vida ("ya no quiero ser investigador"). Entendemos que las representaciones previas se articulan en oposiciones que es necesario comprender en relación con las expectativas y proyectos de vida. Oposiciones como mundo real/mundo académico o teoría/ práctica están íntimamente ligadas con aquello que las personas entrevistadas esperaban encontrar en la carrera elegida y que luego no fue confirmado por su experiencia estudiantil.

Carli, S. (2012), El estudiante universitario. Hacia una historia del presente de la educación pública, Buenos Aires, Siglo XXI.

Cordero, S., M. Ros y M. Cháves (1997), "Un trabajo sobre las representaciones de los ingresantes a la carrera de Antropología", Ponencia presentada en el V Congreso de Antropología Social, La Plata, Universidad Nacional de La Plata <https://equiponaya.com.ar/congresos/ contenido/laplata/LP2/20.htm> [Consulta: julio de 2019].

Danto, A. (2012), Después del fin del arte. El arte contemporáneo y el linde de la historia, Buenos Aires, Paidós.

Daraio, T. (2014), "Las representaciones sociales y las 
trayectorias científicas. Un estudio de caso con estudiantes y graduados de carreras de ciencias exactas y naturales", Tesis de maestría, Buenos Aires, UNSAM.

De Certeau, M. (2000), La invención de lo cotidiano I. Artes de hacer, México, Universidad Iberoamericana.

Ferrarós di Stéfano, J. J. (2010), Práctica profesional: satisfacción y malestar en el trabajo. Práctica docente en Ciencias de la Comunicación, Buenos Aires, Bibliográfika.

Ferrarós, J. J., M. J. Acevedo, V. Altieri y M. Amati (2010), "Entre los medios y la crítica académica. Representaciones sociales del licenciado en Ciencias de la Comunicación", en J. J. Ferrarós, Práctica profesional: satisfacción y malestar en el trabajo. Práctica docente en Ciencias de la Comunicación, Buenos Aires, Bibliográfika, pp. 95-150.

Foucault, M. (2002), La arqueología del saber, Buenos Aires, Siglo XXI.

Foucault, M. (1994), Dichos y Escritos, Vol. I, París, Gallimard.

Latour, B. y S. Woolgar (1995), La vida en el laboratorio. La construcción de los hechos científicos, Madrid, Alianza.

Legarralde, T., A. Vilches y G. Darrigran (2009), "Los científicos según la mirada de los estudiantes de secundaria", Ponencia presentada en las II Jornadas de Enseñanza e Investigación Educativa en el campo de las Ciencias Exactas y Naturales, La Plata, FaHCE, pp. 170-175.

Marková, I. (1996), "En busca de las dimensiones epistemológicas de las representaciones sociales”, en D. Páez y A. Blanco, La teoría sociocultural y la psicología social actual, Madrid, Aprendizaje.

Marradi, A., N. Archenti y J. Piovani (2007), Metodología de las ciencias sociales, Buenos Aires, Emecé.
Moscovici, S. y R. Farr (1984), Social representations, Nueva York, Cambridge University Press.

Panaia, M. (2013), Abandonar la universidad con o sin título, Buenos Aires, Miño y Dávila.

Perera Pérez, M. (2003), “A propósito de las representaciones sociales: apuntes teóricos, trayectoria y actualidad", en CD Caudales, La Habana, CIPS.

Remedi Allione, E. (2004), "La institución: un entrecruzamiento de textos", en E. Remedi Allione, Instituciones educativas. Sujetos, historia e identidades, México, Plaza y Valdez, pp. 25-58.

Rizo García, M. (2012), Imaginarios sobre comunicación. Algunas certezas y muchas incertidumbres en torno a los estudios de comunicación, hoy, Bellaterra, Institut de la Comunicació, Universitat Autònoma de Barcelona.

Santos Sharpe, A. y S. Carli (2016), "Estudios globales y locales sobre el abandono de los estudios universitarios. Teorías, perspectivas y nuevos abordajes", RAES Revista Argentina de Educación Superior, vol. 8, núm. 13, pp. 6-31, <http://www.revistaraes.net/revistas/raes13_ artl.pdf $>$ [Consulta: julio de 2019].

Santos Sharpe, A. (2019), "Discontinuar (en) la universidad. Análisis de experiencias de discontinuidad de los estudios universitarios en distintos campos disciplinales a partir de relatos de vida”, en Ernesto Meccia (ed.), Biografiasy sociedad. Métodos para la producción y el análisis de datos biográficos, Buenos Aires-Santa Fe, EUDEBA-UNL.

Sautu, R., P. Boniolo e I. Perugorría (2007), "Las representaciones sociales de la corrupción en la clase media", en R. Sautu, Práctica de la investigación cuantitativa y cualitativa. Articulación entre teoría, los métodos y las técnicas, Buenos Aires, Lumiere, pp. 249-265.

\section{Cómo citar este artículo:}

Santos-Sharpe, Andrés (2021), "Representaciones de cuatro carreras de la Universidad de Buenos Aires y su vínculo con el abandono de estudios", Revista Iberoamericana de Educación Superior (RIES), vol. XII, núm. 34, pp. 21-45, DOI: https://doi. org/10.22201/iisue.20072872e.2021.34.977 [Consulta: fecha de última consulta]. 